\title{
ADENOSINE-ENHANCED ISCHEMIC PRECONDITIONING PROVIDES ENHANCED POSTISCHEMIC RECOVERY AND LIMITATION OF INFARCT SIZE IN THE RABBIT HEART
}

James D. McCully, PhD

Masahisa Uematsu, MD

Robert A. Parker, ScD

Sidney Levitsky, MD
Objective: The purpose of this study was to determine the effect of an intracoronary bolus injection of adenosine used in concert with ischemic preconditioning on postischemic functional recovery and infarct size reduction in the rabbit heart and to compare adenosine-enhanced ischemic preconditioning with ischemic preconditioning and magnesium-supplemented potassium cardioplegia. Methods: New Zealand White rabbits $(n=$ 36) were used for Langendorff perfusion. Control hearts were perfused at $37^{\circ} \mathrm{C}$ for 180 minutes; global ischemic hearts received 30 minutes of global ischemia and 120 minutes of reperfusion; magnesium-supplemented potassium cardioplegic hearts received cardioplegia 5 minutes before global ischemia; ischemic preconditioned hearts received 5 minutes of zero-flow global ischemia and 5 minutes of reperfusion before global ischemia; adenosine-enhanced ischemic preconditioned hearts received a bolus injection of adenosine just before the preconditioning. To separate the effects of adenosine from adenosine-enhanced ischemic preconditioning, a control group received a bolus injection of adenosine $\mathbf{1 0}$ minutes before global ischemia. Results: Infarct volume in global ischemic hearts was $32.9 \% \pm$ $5.1 \%$ and $\mathbf{1 . 0 3 \%} \pm \mathbf{0 . 3} \%$ in control hearts. The infarct volume decreased $(\mathbf{1 0 . 2 3 \%} \pm \mathbf{2 . 6 \%}$ and $\mathbf{7 . 0 \%} \pm \mathbf{1 . 6 \%}$, respectively; $p<0.001$ versus global ischemia) in the ischemic preconditioned group and control group, but this did not enhance postischemic functional recovery. Magnesium-supplemented potassium cardioplegia and adenosine-enhanced ischemic preconditioning significantly decreased infarct volume $(2.9 \% \pm 0.8 \%$ and $2.8 \% \pm$ $0.55 \%$, respectively; $p<0.001$ versus global ischemia, $p=0.02$ versus ischemic preconditioning and $p=0.05$ versus control group) and significantly enhanced postischemic functional recovery. Conclusions: Adenosineenhanced ischemic preconditioning is superior to ischemic preconditioning and provides equal protection to that afforded by magnesium-supplemented potassium cardioplegia. (J Thorac Cardiovasc Surg 1998;116:154-62)
$M$ urry and colleagues ${ }^{1}$ were the first to describe an endogenous myocardial protection, ischemic preconditioning (IPC), in which the imposition of

From the Division of Cardiothoracic Surgery and Biometrics Center, Beth Israel Deaconess Medical Center and Harvard Medical School, Boston, Mass.

This study was supported by the National Institutes of Health (HL 29077) and the American Heart Association.

Received for publication April 17, 1997; revisions requested June 6, 1997; revisions received Feb. 11, 1998; accepted for publication Feb. 19, 1998.

Address for reprints: James D. McCully, PhD, Division of Cardiothoracic Surgery, Beth Israel Deaconess Medical Center, 110 Francis St., Suite 2C, Boston, MA 02215.

Copyright (C) 1998 by Mosby, Inc.

$0022-5223 / 98 \$ 5.00+0 \quad \mathbf{1 2 / 1 / 8 9 8 0 6}$ one or more brief periods of ischemia (3 to 5 minutes) followed by reperfusion "preconditions" the heart in such a way that infarct size and myocardial necrosis are significantly reduced during the subsequent induction of sublethal ischemia. The induction of endogenous myocardial protection via preconditioning would appear to be common in all species studied in the reduction of myocardial infarct volume. However, the effects of preconditioning on postischemic myocardial functional recovery have been shown to vary among species in contrast with the protection afforded by cardioplegia. ${ }^{2-5}$ In the rat heart the use of preconditioning has been shown to both reduce myocardial infarction and enhance postischemic myocardial functional recovery. ${ }^{3,5,6}$ In contrast, in the rabbit heart, although 
preconditioning has been shown to reduce myocardial infarction, no enhancement of postischemic myocardial functional recovery occurs. ${ }^{4,7,8}$

Downey ${ }^{9}$ has proposed that adenosine, a ubiquitous biologic compound that is formed as a consequence of the breakdown of high-energy phosphate (adenosine triphosphate) during preconditioning, plays a central role both as a mediator and as a trigger in the cardioprotection afforded by IPC and that continued occupancy of adenosine receptors during ischemia is required before preconditioning can be achieved.

Recently, it has been shown in the in vivo dog heart that exogenous adenosine enhanced postischemic myocardial functional recovery, when administered via intracoronary infusion. ${ }^{10}$ These data agree with previous reports that indicate that there are differential responses to steady state as compared with bolus adenosine injections. ${ }^{11,12} \mathrm{In}$ human patients, adenosine has been shown to cause pain and discomfort. ${ }^{12}$ Langervist and colleagues ${ }^{11}$ have shown that adenosine, when delivered by steady-state infusion, was associated with myocardial ischemia as determined by lactate production, ST-segment depression, and chest pain. The delivery of adenosine by intracoronary bolus injection was found to obviate these effects. ${ }^{11}$

Using these preliminary studies as a paradigm, we speculated that the use of an intracoronary bolus injection of adenosine when used in concert with IPC (adenosine-enhanced ischemic preconditioning [APC]) may allow for enhanced myocardial protection in the rabbit heart. Our results indicate that APC decreases myocardial infarct size and enhances postischemic functional recovery in the rabbit heart. In addition, our results indicate that APC is as efficacious as magnesium-supplemented potassium cardioplegia.

\section{Methods}

Animals and chemicals. New Zealand White rabbits ( $n=36 ; 15$ to 20 weeks; Millbrook Farm, Amherst, Mass.) were housed individually and provided with laboratory food and water as necessary. All experiments were approved by the Beth Israel Deaconess Medical Center Animal Care and Use Committee and conformed to the United States National Institutes of Health guidelines regulating the care and use of laboratory animals (NIH Publication No. 85-23, revised 1985). All chemicals used were of electrophoresis grade or ultra-pure quality.

Langendorff perfusion. All rabbits were anesthetized with sodium pentobarbital (Pentobarbital; Veterinary Laboratories, Inc., Lenexa, Kan.; $100 \mathrm{mg} / \mathrm{kg}$ intravenously) and heparin (200 unit/kg intravenously) via a marginal ear vein. The heart was excised and used for Langendorff perfusion as previously described. ${ }^{13,14}$ The hearts were paced via the right atrium at $180 \pm 3$ beats/min throughout the experiment with a Medtronic model 5330 stimulator (Medtronic, Inc., Minneapolis, Minn.). Left ventricular systolic pressure, left ventricular peak developed pressure, left ventricular end-diastolic pressure, and coronary flow were continuously recorded. Hemodynamic variables were acquired with a PO-NEMAH digital data acquisition system with an Acquire Plus processor board and left ventricular pressure analysis software (Gould, Valley View, Ohio).

Experimental protocol. Hearts were perfused for 20 minutes to establish equilibrium hemodynamics. Equilibrium was ceased when heart rate, coronary flow, left ventricular pressure, and diastolic pressure were maintained at the same level for three continuous measurement periods timed 5 minutes apart. After 20 minutes of equilibrium perfusion, the hearts were divided into four groups; control and global ischemia hearts received 30 minutes of equilibrium perfusion to allow for standardization of experimental conditions. Control hearts $(n=6)$ were perfused without global ischemia at $37^{\circ} \mathrm{C}$ for 180 minutes. Global ischemia hearts $(n=6)$ were subjected to 30 minutes of ischemia and 120 minutes of reperfusion. Global ischemia was achieved by crossclamping of the aorta. Magnesium-supplemented potassium (K/Mg) cardioplegia hearts $(n=6)$ were infused with $\mathrm{K} / \mathrm{Mg}(20$ $\mathrm{mmol} / \mathrm{L}$ each $\mathrm{KCl}$ and $\mathrm{MgSO}_{4}$ ) then subjected to 30 minutes of ischemia and 120 minutes of reperfusion. Cardioplegic solution was perfused at a constant pressure of $75 \mathrm{~cm}$ of water at $37^{\circ} \mathrm{C}$ for 5 minutes before the onset of 30 minutes of global ischemia and 120 minutes of reperfusion. IPC hearts $(n=6)$ received 5 minutes of zero-flow global ischemia followed by 5 minutes of reperfusion before 30 minutes of global ischemia and 120 minutes of reperfusion. APC hearts $(n=6)$ received a 10 $\mathrm{ml}$ bolus injection of $1 \mathrm{mmol} / \mathrm{L}$ adenosine in Krebs buffer (concentration determined from preliminary investigations) just before preconditioning ( 5 minutes of zero-flow global ischemia followed by 5 minutes of reperfusion). The bolus was injected into the aortic root via a sidearm cannula located proximal to the perfusion cannula. To separate the effects of adenosine from that of APC, a control group (adenosine only [ADO]; $n=6$ ) received a $10 \mathrm{ml}$ bolus injection of $1 \mathrm{mmol} / \mathrm{L}$ adenosine in Krebs buffer 10 minutes before global ischemia and reperfusion. All hearts were paced continuously via the right atrium at $180 \pm$ 3 beats/min throughout the experiment, with a Medtronic rapid atrial pacer (5330; Medtronic, Minneapolis, Minn.). Rabbits were assigned randomly to treatment groups.

Comparison of wet and dry weights. Left ventricular tissue samples (approximately $0.1 \mathrm{gm}$ ) from all experimental groups were weighed (wet weight), dried at $80^{\circ} \mathrm{C}$ for 24 hours for reweighing (dry weight), and then used for the determination of dry/wet weight ratios, with the use of previously described methods. ${ }^{13}, 14$

Measurement of infarct size. After reperfusion, hearts were rapidly removed from the perfusion apparatus and sliced across the long axis of the left ventricle, from apex to base, into $2 \mathrm{~mm}$ thick transverse sections and then incubated in $1 \%$ triphenyl tetrazolium chloride (Sigma 
Chemical Co., St. Louis, Mo.) in phosphate buffer $(\mathrm{pH}$ $7.4)$ at $38^{\circ} \mathrm{C}$ for 20 minutes. $^{15}$ Infarct areas were enhanced by storage in $10 \%$ formaldehyde solution for 24 hours before final measurement. ${ }^{5,15}$ In the global ischemia heart, the whole ventricle is at risk of infarction and therefore collateral flow and estimation of the area at risk was not required. ${ }^{5,15}$ A copy of the stained heart slices was traced onto a clear acetate sheet over a glass plate under room light. The area of left ventricle and the area of infarcted tissue were measured by an independent, blinded observer using planimetry. The volumes of the infarcted zone and the area at risk were calculated by multiplying the planimetered areas by the slice thickness. ${ }^{5,15}$ Infarct volume was expressed as a percentage of left ventricular volume for each heart. ${ }^{5,15}$

Statistical analysis. Statistical analysis was performed using the SAS (version 6.12) software package (SAS Institute, Inc., Cary, N.C.). The mean \pm the standard error of the mean for all data was calculated for all variables. Statistical significance was determined with repeated-measures analysis of variance with the group as a "between subjects" factor and time as a "within subjects" factor. Post hoc comparisons between groups for both the average effect and at individual time points were made with the use of a Bonferroni correction to adjust for the multiplicity of tests. A one-way analysis of variance was used for area of infarction.

\section{Results}

Determination of adenosine concentration used for bolus injection. The concentration of adenosine used for bolus injection $(1 \mathrm{mmol} / \mathrm{L})$ was determined from preliminary investigation with adenosine concentrations 0.1 to $10 \mathrm{mmol} / \mathrm{L}$. It was determined that an adenosine concentration less than $2.5 \mathrm{mmol} / \mathrm{L}$ but greater than $0.1 \mathrm{mmol} / \mathrm{L}$ was required as a bolus injection with IPC to enhance postischemic functional recovery (results not shown).

Equilibrium hemodynamics. No significant differences in heart rate, left ventricular systolic pressure, left ventricular end diastolic pressure (LVEDP), left ventricular peak developed pressure (LVPDP), positive rate of pressure rise $(\mathrm{dP} / \mathrm{dt})$, or coronary flow were observed between or within groups after equilibrium.

Left ventricular end-diastolic pressure. The effects of APC, IPC, and $\mathrm{K} / \mathrm{Mg}$ cardioplegia on LVEDP during equilibrium, 30 minutes of normothermic global ischemia, and 120 minutes of reperfusion are shown in Fig. 1 and Table I. LVEDP in APC and IPC hearts decreased to $0 \mathrm{~mm} \mathrm{Hg}$ during IPC and then returned to the control level during the 5 minutes of reperfusion before the induction of global ischemia. No significant difference in LVEDP was found between groups before 30 minutes of global ischemia (Fig. 1). The use of APC or K/Mg cardioplegia maintained LVEDP at the control levels throughout reperfusion. LVEDP after $20 \mathrm{~min}-$ utes of normothermic global ischemia was significantly increased in global ischemia and IPC hearts as compared with control hearts (Table I). LVEDP in ADO control hearts increased progressively during reperfusion with maximal LVEDP being observed at 120 minutes of reperfusion (180 minutes of perfusion). Between-group comparison of LVEDP during reperfusion (70 to 180 minutes) indicated that there was no significant difference between the control, ADO, K/Mg, or APC groups. A significant difference between control versus global ischemia $(p<0.001)$ and IPC $(p<0.001)$, ADO versus global ischemia $(p<0.001)$ and IPC $(p=0.01), \mathrm{K} / \mathrm{Mg}$ versus global ischemia $(p<0.001)$ and IPC $(p<$ $0.001)$, and APC versus global ischemia $(p<0.001)$ and IPC $(p<0.001)$ was observed.

Left ventricular peak developed pressure. LVPDP in APC, ADO, and IPC hearts decreased to $0 \mathrm{~mm} \mathrm{Hg}$ during IPC and then returned to control levels during the 5-minute reperfusion period before the induction of global ischemia (Fig. 2). No significant difference from control was observed between groups before the start of global ischemia. During the first 10 minutes of reperfusion, LVPDP in APC hearts was significantly decreased as compared with control $(p=0.01)$ and $\mathrm{K} / \mathrm{Mg}(p=0.01)$ hearts, but after 20 minutes of reperfusion $(80$ minutes of perfusion) no significant difference between APC, $\mathrm{K} / \mathrm{Mg}$, and control groups was observed. However, LVPDP in global ischemia, ADO, and IPC hearts was significantly decreased as compared with control hearts throughout reperfusion (70 to $180 \mathrm{~min}$ utes; Table I).

Between-group comparison of LVPDP during reperfusion (70 to 180 minutes) indicated that there was no significant difference between control, $\mathrm{K} / \mathrm{Mg}$, and APC groups. A significant difference between control versus global ischemia $(p<0.001)$, IPC ( $p<$ $0.001)$, and $\operatorname{ADO}(p=0.001) ; \mathrm{K} / \mathrm{Mg}$ versus global ischemia $(p<0.001)$, IPC $(p<0.001)$, and ADO $(p=0.002)$; and APC versus global ischemia $(p<$ $0.001)$ and IPC $(p=0.02)$ was observed. Similar results were observed for left ventricular $\mathrm{dP} / \mathrm{dt}$ (results not shown).

Coronary flow. Coronary flow in APC and IPC hearts decreased to $0 \mathrm{ml} / \mathrm{min}$ during IPC and then returned to the control level during the 5-minute reperfusion period (Fig. 3). No significant difference in coronary flow was found among groups before 30 minutes of global ischemia. No significant difference 


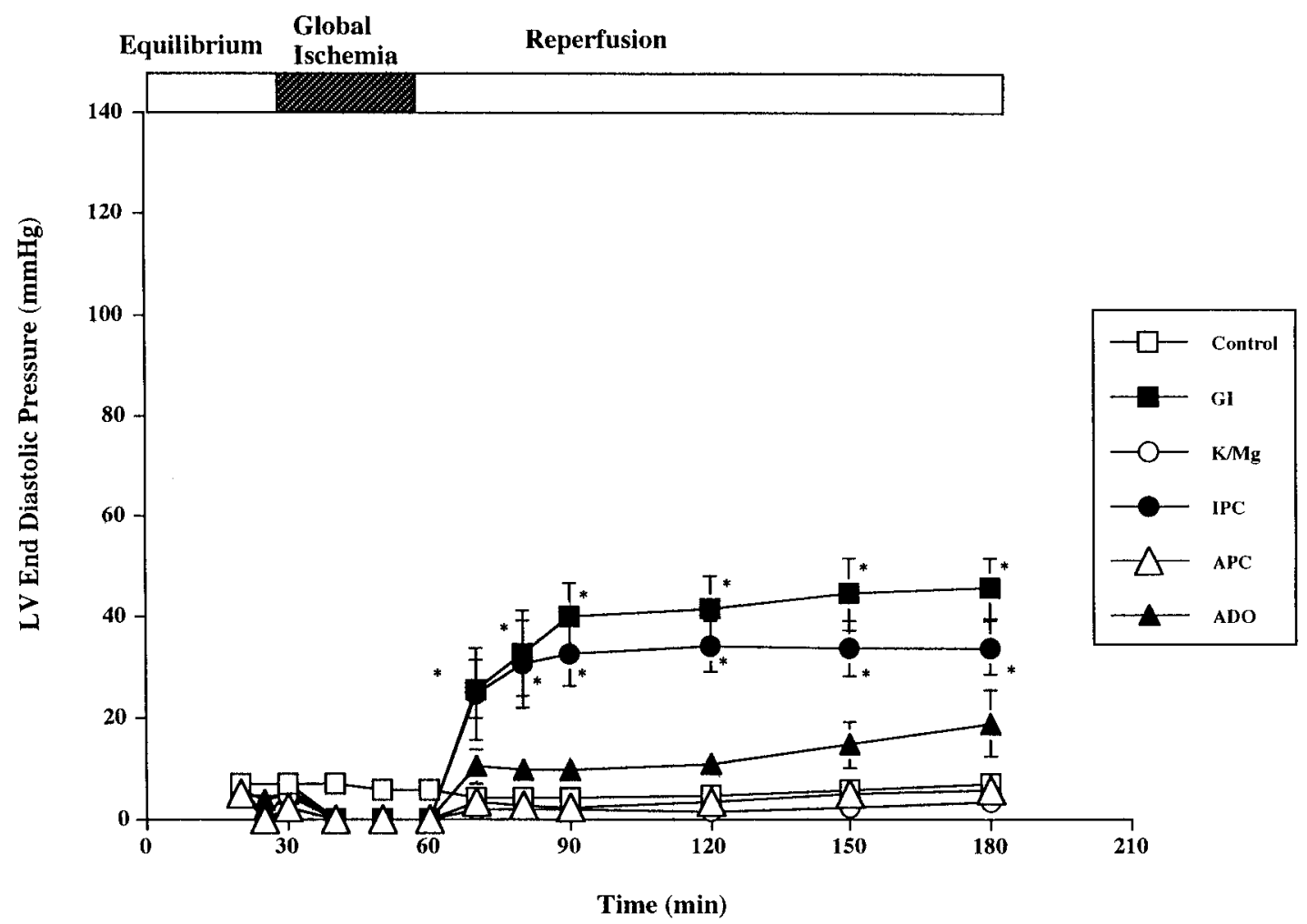

Fig. 1. The effects of APC, IPC, and ADO on LVEDP during 30 minutes of global ischemia (GI) and 120 minutes of reperfusion and comparison with $\mathrm{K} / \mathrm{Mg}$ cardioplegia. Results are shown as the mean and standard error of the mean for each group $(n=6) .{ }^{*}$ Significant differences (see Table I) versus control hearts.

in coronary flow was found during reperfusion between the control, APC, and $\mathrm{K} / \mathrm{Mg}$ hearts (Table I). Coronary flow was significantly increased throughout reperfusion (70 to 180 minutes) in global ischemia hearts and in ADO hearts after 60 minutes of reperfusion (120 to 180 minutes of perfusion; Table I). Between-group comparison of coronary flow during reperfusion (70 to 180 minutes) indicated that there was no significant difference between the control, IPC, $\mathrm{K} / \mathrm{Mg}$, and APC groups. A significant difference between control versus global ischemia $(p<0.001)$ and $\operatorname{ADO}(p=0.01), \mathrm{K} / \mathrm{Mg}$ versus global ischemia $(p=0.002)$, and APC versus global ischemia $(p=0.001)$ was observed.

Myocardial infarct volume. A significant increase $(p<0.001)$ in infarct volume expressed as a percent of ventricular volume was observed in global ischemia hearts $(32.9 \% \pm 5.1 \%)$ as compared with control hearts $(1.03 \% \pm 0.3 \%$; Fig. 4). Infarct volume in IPC hearts $(10.23 \% \pm 2.6 \%)$ was significantly decreased as compared with global ischemia hearts $(p<0.001)$ but was significantly increased $(p=0.01)$ as compared with control hearts. In ADO hearts, infarct volume was $7.0 \% \pm 1.6 \%$, which was significantly decreased $(p<0.001)$ as compared with global ischemia hearts but was not significantly different from IPC hearts. Infarct volume was significantly decreased to $2.9 \% \pm 0.8 \%$ and $2.8 \% \pm$ $0.55 \%$ for $\mathrm{K} / \mathrm{Mg}$ and APC hearts, respectively $(p<$ $0.001, p=0.05, p=0.02$ for $\mathrm{K} / \mathrm{Mg}$ hearts as compared to global ischemia, ADO and IPC hearts and $\mathrm{p}<0.001, p=0.05, p=0.02$ for APC hearts as compared with global ischemia, ADO, and IPC hearts). No difference in infarct volume between control, $\mathrm{K} / \mathrm{Mg}$, and APC hearts was observed. No significant differences in dry weight/wet weight ratios were found between any group.

\section{Discussion}

Previous investigation by others has shown that IPC reduces infarct size but does not enhance postischemic myocardial functional recovery in the rabbit heart. ${ }^{4,5,7,8}$ Although the mechanism(s) by which IPC affords cardioprotection remain to be 
Table I. Hemodynamic data

\begin{tabular}{|c|c|c|c|c|c|c|c|c|c|c|c|c|c|}
\hline & \multirow[b]{2}{*}{ Group } & \multicolumn{12}{|c|}{ Time (min) } \\
\hline & & 70 & $\begin{array}{c}p \\
\text { Value }\end{array}$ & 80 & $\begin{array}{c}p \\
\text { Value }\end{array}$ & 90 & $\begin{array}{c}p \\
\text { Value }\end{array}$ & 120 & $\begin{array}{c}p \\
\text { Value }\end{array}$ & 150 & $\begin{array}{c}p \\
\text { Value }\end{array}$ & 180 & $\begin{array}{c}p \\
\text { Value }\end{array}$ \\
\hline \multirow{6}{*}{$\begin{array}{l}\text { LVPDP } \\
\qquad(\mathrm{mm} \mathrm{Hg})\end{array}$} & Control & $119.5(5.9)$ & & $120.1(6.0)$ & & $119.3(5.6)$ & & $114.8(6.1)$ & & $105.5(7.4)$ & & $99.3(6.8)$ & \\
\hline & GI & $30.8(8.0)$ & $<0.001$ & $40.8(6.2)$ & $<0.001$ & $49.6(7.7)$ & $<0.001$ & $47.6(8.4)$ & $<0.001$ & $44.0(8.2)$ & $<0.001$ & $42.3(9.2)$ & 0.001 \\
\hline & IPC & $54.8(4.9)$ & $<0.001$ & $59.8(6.3)$ & $<0.001$ & $61.1(7.0)$ & $<0.001$ & $63.3(9.9)$ & $<0.001$ & $61.8(10.9)$ & 0.01 & 59.3 & 0.04 \\
\hline & $\mathrm{ADO}$ & 61.3 (3.9) & $<0.001$ & 79.0 & $<0.001$ & 82.1 (5.1) & 0.002 & 75.1 (7.4) & 0.01 & 66.8 (7.9) & 0.02 & 56.1 & 0.02 \\
\hline & $\mathrm{K} / \mathrm{Mg}$ & 99.3 (3.4) & 0.15 & $120.1(2.5)$ & 1.00 & $126.6(1.3)$ & 1.00 & $125.1(3.5)$ & 1.00 & $115.8(4.7)$ & 1.00 & 112.6 & 1.00 \\
\hline & $\mathrm{APC}$ & $69.8(2.8)$ & $<0.001$ & $93.5(4.8)$ & 0.02 & $101.1(6.2)$ & 0.54 & $100.1(6.1)$ & 1.00 & $99.4(6.0)$ & 1.00 & $93.0(9.4)$ & 1.00 \\
\hline \multirow{6}{*}{$\begin{array}{l}\text { LVEDP } \\
\qquad(\mathrm{mm} \mathrm{Hg})\end{array}$} & Control & 4.5( & & 8) & & $4.3(0.9)$ & & $4.8(1.1)$ & & $6.0(1.4)$ & & 7.0 & \\
\hline & GI & $25.6(5.8)$ & 0.05 & $32.6(8.4)$ & 0.01 & $39.8(6.8)$ & $<0.001$ & $41.3(6.8)$ & $<0.001$ & $44.5(7.2)$ & $<0.001$ & $45.6(6.1)$ & $<0.001$ \\
\hline & IPC & $24.6(8.9)$ & 0.07 & $30.6(8.6)$ & 0.02 & $32.3(6.2)$ & $<0.001$ & $34.0(5.2)$ & $<0.001$ & $33.6(5.3)$ & 0.001 & $33.8(5.3)$ & 0.003 \\
\hline & ADO & $10.5(3.4)$ & 1.00 & $10.0(2.9)$ & 1.00 & $9.8(2.8)$ & 1.00 & $11.0(3.1)$ & 1.00 & $14.8(4.5)$ & 1.00 & $19.0(6.4)$ & 1.00 \\
\hline & $\mathrm{K} / \mathrm{Mg}$ & $2.1(0.6)$ & 1.00 & $2.0(0.6)$ & 1.00 & $2.0(0.6)$ & 1.00 & $1.8(0.6)$ & 1.00 & $2.3(1.0)$ & 1.00 & $3.5(1.9)$ & 1.00 \\
\hline & $\mathrm{APC}$ & $3.6(1.2)$ & 1.00 & $3.0(1.1)$ & 1.00 & $2.6(1.2)$ & 1.00 & $3.8(1.5)$ & 1.00 & $5.1(2.2)$ & 1.00 & $6.0(2.5)$ & 1.00 \\
\hline \multirow{6}{*}{$\begin{array}{l}\text { Coronary } \\
\text { flow } \\
(\mathrm{ml} / \mathrm{min})\end{array}$} & Control & $45.0(2.5)$ & & $43.6(2.8)$ & & $45.5(3.1)$ & & $45.0(2.5)$ & & $42.8(2.6)$ & & $42.8(3.5)$ & \\
\hline & GI & $26.1(4.0)$ & 0.01 & $29.0(3.0$ & 0.02 & $27.6(2.7)$ & 0.002 & $24.0(2.4)$ & $<0.001$ & $20.6(2.9)$ & $<0.001$ & $18.0(3.1)$ & $<0.001$ \\
\hline & IPC & 39.1 (4.0) & 1.00 & $33.5(2.5)$ & 0.33 & $32.3(2.3)$ & 0.05 & 31.5 (1.9) & 0.05 & 29.0 (1.8) & 0.06 & $27.8(1.5)$ & 0.06 \\
\hline & $\mathrm{ADO}$ & $36.0(2.4)$ & 1.00 & $34.8(1.4)$ & 0.66 & $34.0(1.8)$ & 0.13 & $30.3(2.7)$ & 0.02 & $24.8(2.3)$ & 0.004 & $22.5((2.5)$ & 0.003 \\
\hline & $\mathrm{K} / \mathrm{Mg}$ & $39.6(4.8)$ & 1.00 & $39.1(4.5)$ & 1.00 & $41.3(4.1)$ & 1.00 & $43.1(4.0)$ & 1.00 & $41.5(4.0)$ & 1.00 & $40.0(4.4)$ & 1.00 \\
\hline & APC & $47.1(3.1)$ & 1.00 & $44.5(2.6)$ & 1.00 & $44.6(2.4)$ & 1.00 & $43.0(3.5)$ & 1.00 & $39.0(4.1)$ & 1.00 & $36.5(4.3)$ & 1.00 \\
\hline
\end{tabular}

Measurements significantly different from the control are shown in bold type. GI, Global ischemia.

fully elucidated, a sufficient body of evidence exists to indicate that adenosine plays a central role in this process. ${ }^{9,16-18}$ Several potential beneficial effects of IPC have been ascribed to adenosine. ${ }^{19}$ Adenosine, by its property to antagonize calcium channels, has been shown to inhibit the sinoatrial and the atrioventricular nodes and myocardial contraction, thereby inducing cardiac arrest. ${ }^{20}$ Adenosine has also been implicated in the protection afforded against myocardial infarction ("second window of protection") observed 24 hours after the imposition of IPC. ${ }^{17}$ In rabbit hearts it has been shown that a 5-minute infusion with adenosine followed by a 10 -minute washout before ischemia reduced infarct size from $41 \%$ to $25 \%$ as compared with $10 \%$ in IPC-treated hearts. ${ }^{18}$ However, the transient infusion of adenosine followed by washout has been shown to be ineffectual in attenuating myocardial stunning. ${ }^{7,21}$

In our investigations, we have used $1 \mathrm{mmol} / \mathrm{L}$ adenosine for bolus injection, but this concentration may not be optimal. In preliminary experiments, serial dilutions of adenosine $(0.1$ to $10 \mathrm{mmol} / \mathrm{L})$ were used for bolus injection. Our results indicated that a concentration greater than $0.1 \mathrm{mmol} / \mathrm{L}$ and less than $2.5 \mathrm{mmol} / \mathrm{L}$ was sufficient to allow for both enhanced postischemic functional recovery and decreased infarct volume. No cardioprotective effects were seen when adenosine concentration was less than $0.1 \mathrm{mmol} / \mathrm{L}$, although adenosine concentrations of more than $2.5 \mathrm{mmol} / \mathrm{L}$ were found to induce arrhythmia and fibrillation (results not shown).

Previous studies have suggested that enhanced collateral flow during global ischemia would limit the degree of ischemic injury and facilitate postischemic functional recovery. ${ }^{22}$ We have used the rabbit heart, which has no known collateral blood flow, and we have used global ischemia, which would rule out any supplementary coronary flow during ischemia and which might contribute to myocardial protection. It is possible that the enhanced functional recovery observed with APC is the result of increased coronary flow during reperfusion, and this effect cannot be excluded. Kloner and colleagues ${ }^{23}$ have previously suggested that myocyte injury occurs before vascular injury, although Hearse and colleagues ${ }^{24}$ have proposed that altered (increased) vasoconstriction precedes and contributes to myocyte injury and necrosis. Our results indicate that a direct correlation between coronary flow and enhanced postischemic functional recovery is evident but that no relationship to myocyte injury is evident. Coronary flow in APC and $\mathrm{K} / \mathrm{Mg}$ hearts returned rapidly to the control level during reperfusion and remained at this level throughout reperfusion and was associated with both increased postischemic functional recovery and decreased infarct volume. In contrast with ADO, coronary flow in IPC and 


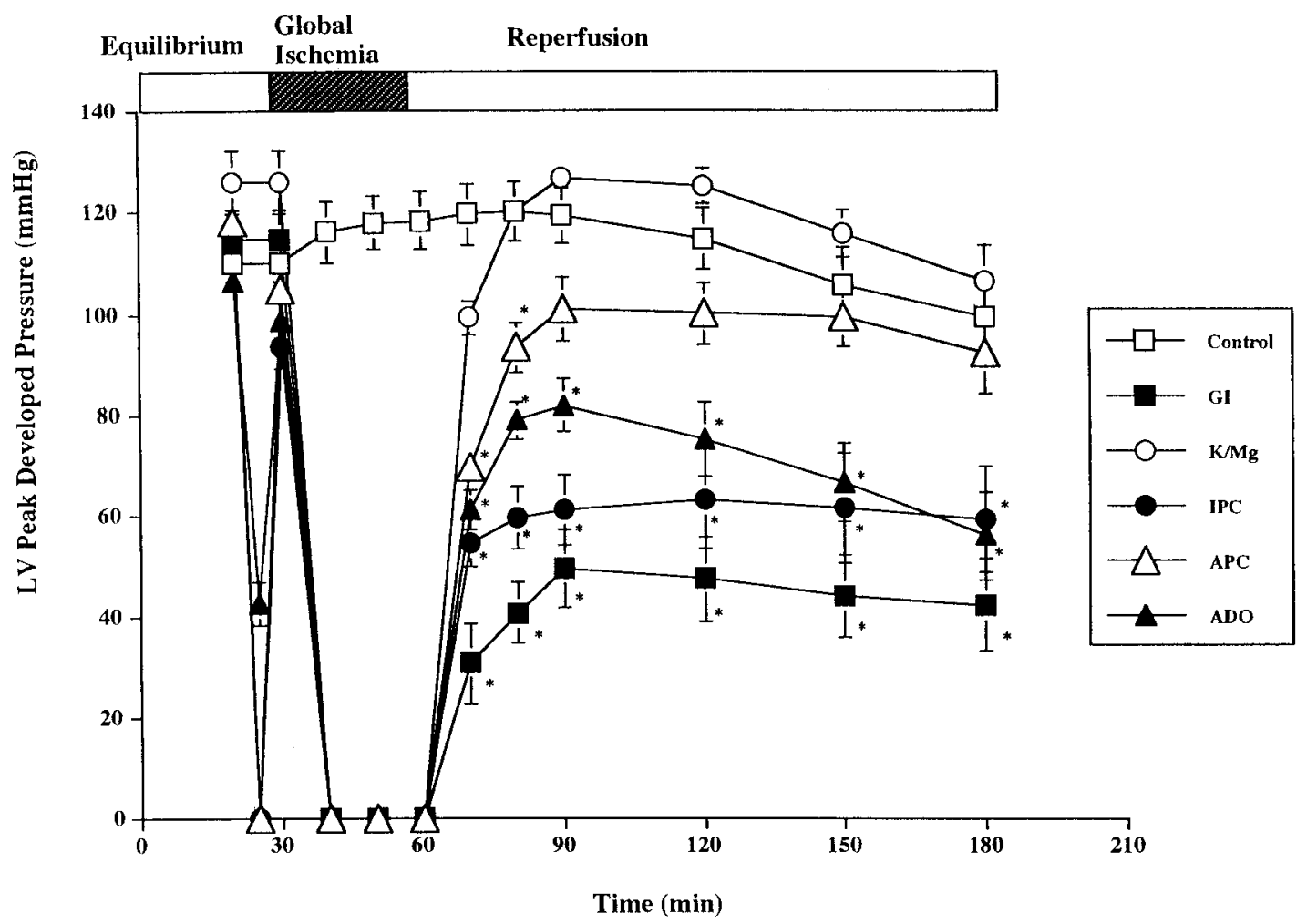

Fig. 2. The effects of APC, IPC, and ADO on LVPDP during 30 minutes of global ischemia (GI) and 120 minutes of reperfusion and comparison with $\mathrm{K} / \mathrm{Mg}$ cardioplegia. Results are shown as the mean and standard error of the mean for each group $(n=6) .{ }^{*}$ Significant differences (see Table I) versus control hearts.

global ischemia hearts was decreased as compared with control hearts throughout reperfusion and was associated with decreased postischemic myocardial functional recovery; however, infarct volume was decreased in both IPC and ADO hearts. These results would agree with previous reports that indicated that the effects of adenosine infusion are relatively short lived and suggest that the results observed are associated with the additive effects of adenosine and IPC. ${ }^{16,18,20,25}$ In our model with constant pacing, the heart rate was not altered by adenosine infusion nor was initial coronary flow. The effects of $\mathrm{K} / \mathrm{Mg}$ cardioplegia on coronary flow have been previously noted and may be related to the amelioration of cytosolic calcium accumulation during ischemia. ${ }^{13,14}$

Mullane and colleagues ${ }^{26}$ have previously noted that, while endogenous adenosine accumulation is central to the cardioprotection afforded by IPC, endogenous concentration is not sufficient to allow for maximal cardioprotection because the administration of exogenous adenosine or its analogs in- creases the degree of cardioprotection. Mentzer and colleagues ${ }^{16}$ have suggested that it is the interstitial fluid levels of adenosine that attenuate preconditioning. The mode of adenosine infusion would appear to be of central importance in the protection afforded by APC. Previous reports have indicated that there are differential responses to steady state as compared with bolus adenosine injections. ${ }^{11,12}$ Infusion of adenosine $(1 \mathrm{mmol} / \mathrm{L}$ for 5 minutes; $n=$ 4; results not shown) reduced infarct size to $9.1 \% \pm$ $2.2 \%$ but was no more effective than $\operatorname{ADO}(p=$ $0.45)$ or IPC $(p=0.77)$ and did not enhance postischemic functional recovery. The inability of adenosine or IPC alone to enhance postischemic myocardial functional recovery coincident with the reduction of myocardial infarct size would suggest that both the endogenous adenosine levels and priming of adenosine receptors may be required for cardioprotection. Our results indicate that the use of an intracoronary bolus adenosine $(1 \mathrm{mmol} / \mathrm{L})$, by itself, significantly decreases myocardial infarct volume in the rabbit heart but does not enhance 


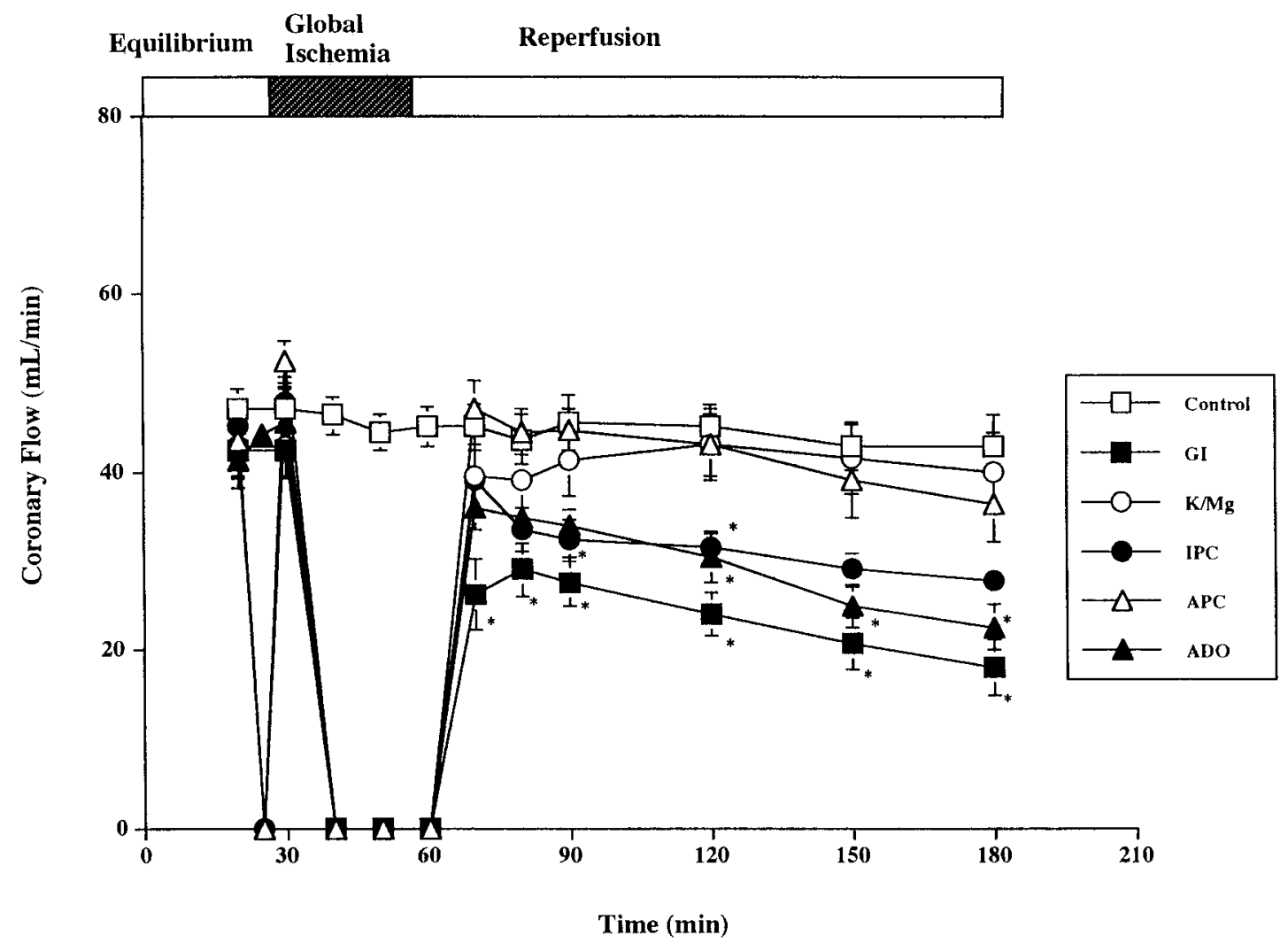

Fig. 3. The effects of APC, IPC, and ADO on coronary flow during 30 minutes of global ischemia (GI) and 120 minutes of reperfusion and comparison to $\mathrm{K} / \mathrm{Mg}$ cardioplegia. Results are shown as the mean and standard error of the mean for each group $(n=6)$. *Significant differences (see Table I) versus control hearts.

postischemic myocardial functional recovery. This would agree with a previous report ${ }^{27}$ that shows no direct inotropic effects are associated with adenosine. Although we have not determined the effect of APC on interstitial adenosine levels, we speculate that APC rapidly increases interstitial adenosine levels greater than that able to be achieved by steady-state infusion, allowing for the rapid saturation of myocardial adenosine receptors, and that the level of adenosine receptor saturation may be directly correlated with both the reduction of myocardial infarct size and the degree of postischemic functional recovery attained. Our results further suggest that the effects of APC are cumulative in that myocardial infarct size reduction is enhanced as compared with either IPC or ADO alone (Fig. 4). The exact mechanism(s), by which APC-enhanced cardioprotection is afforded, however, will require further investigation.

Intrinsic to the development of new myoprotec- tive protocols for use in cardiac surgery are the requirements of new protocols to be equal to or better than conventional cardioplegia in providing for enhanced postischemic functional recovery and decreased myocardial infarct size. ${ }^{6}$ In previous studies, we have shown that the use of $\mathrm{K} / \mathrm{Mg}$ cardioplegia significantly decreases cytosolic calcium accumulation during ischemia and enhances postischemic myocardial functional recovery in both the mature and aged myocardium. ${ }^{13,14}$ In this report we show that $\mathrm{K} / \mathrm{Mg}$ cardioplegia significantly enhances postischemic functional recovery and decreases myocardial infarct size. In addition, we show that $\mathrm{K} / \mathrm{Mg}$ cardioplegia is more effective than IPC $(p<0.001)$ in reducing infarct volume. Of importance is our finding that the use an intracoronary bolus injection of adenosine used in concert with ischemia preconditioning (APC) provides equal cardioprotection to that afforded by $\mathrm{K} / \mathrm{Mg}$ cardioplegia. Our investigations have used an isolated crystalloid buffer-per- 


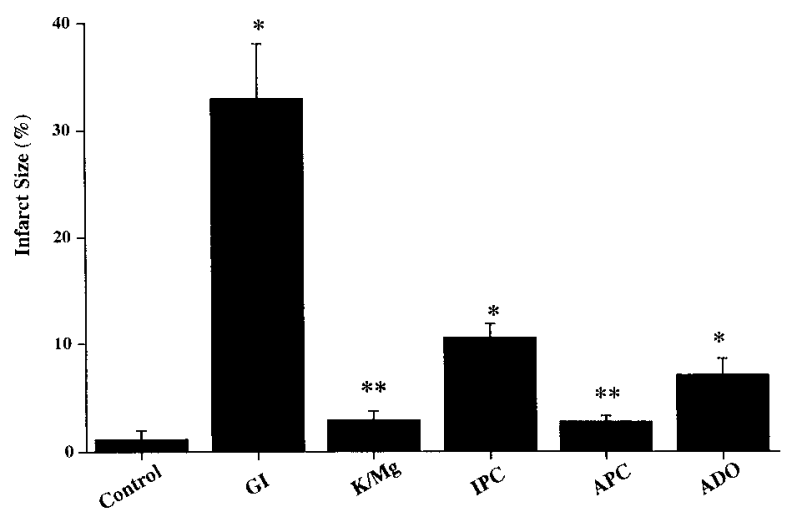

Fig. 4. The effects of APC, IPC, and ADO on infarct size during 30 minutes of global ischemia (GI) and 120 minutes of reperfusion. Results are shown as the mean and standard error of the mean for each group $(n=6)$. *Significant differences $(p<0.001)$ versus global ischemia hearts. **Significant differences for $\mathrm{K} / \mathrm{Mg}$ versus $\mathrm{ADO}$ $(p=0.05)$ and $\mathrm{IPC}(p=0.02)$ and $\mathrm{APC}$ versus $\mathrm{ADO}(p=$ $0.05)$ and IPC $(p=0.02)$. There was no significant difference in infarct size between control, $\mathrm{K} / \mathrm{Mg}$, and APC hearts.

fused rabbit heart model to allow for comparison with previous reports and thus do not account for the intervening benefits of the blood perfused heart. ${ }^{1-9,13,14}$ Previous investigation, comparing crystalloid and blood-perfused rabbit hearts, has shown that blood-perfused hearts exhibit a greater resistance to ischemia and a superior response to cardioplegia as compared with crystalloid-perfused hearts. ${ }^{28}$ Sandhu and colleagues ${ }^{29}$ have shown that IPC is effective in reducing infarct size in both the buffer-perfused and blood-perfused hearts but that infarct size in buffer-perfused hearts was much greater than in crystalloid-perfused hearts. However, it should be noted that no significant improvement in postischemic function was observed with IPC in either buffer-perfused or blood-perfused hearts. Our results show that APC significantly reduces myocardial infarct size and significantly enhances postischemic functional recovery and suggest that APC can be used as an alternative to cardioplegia, affording similar levels of cardioprotection.

\section{REFERENCES}

1. Murry CE, Jennings RB, Reimer KA. Preconditioning with ischemia: a delay of lethal cell injury in ischemic myocardium. Circulation 1986;74:1124-36.

2. Li GC, Vasquez JA, Gallagher KP, Lucchesi BR. Myocardial protection with preconditioning. Circulation 1990;82:609-19.
3. Lasley RD, Anderson GM, Mentzer RM. Ischemic preconditioning enhance postischemic recovery of function in the rat heart. Cardiovasc Res 1993;27:565-70.

4. Cohen MV, Liu GS, Downy JM. Preconditioning causes improved wall motion as well as smaller infarcts after transient coronary occlusion in rabbits. Circulation 1991; 84: 341-9.

5. Jenkins DP, Pugsley WB, Yellon DM. Ischemic preconditioning in a model of global ischemia: infarct size limitation, but no reduction of stunning. J Mol Cell Cardiol 1995;27: 1623-32.

6. Kolocassides KG, Galinanes M, Hearse DJ. Ischemic preconditioning, cardioplegia or both? Differing approaches to myocardial and vascular protection. J Mol Cell Cardiol 1996;28:623-34

7. Asimakis GK, Lick SD, Conti VR. Transient ischemia cannot precondition the rabbit heart against postischemic contractile dysfunction. Ann Thorac Surg 1996;62:543-9.

8. Lasley RD, Noble MA, Koyn PJ, Mentzer RM Jr. Different effects of an adenosine $A_{1}$ analogue and ischemic preconditioning in isolated rabbit hearts. Anal Thorac Surg 1995;60: 1698-703.

9. Downey JM. Ischemic preconditioning: natures own cardioprotective intervention. Trends Cardiovasc Med 1992;2:170-6.

10. Randhawa MPS, Lasley RD, Mentzer RM Jr. Salutary effects of exogenous adenosine on in vivo myocardial stunning. J Thorac Cardiovasc Surg 1995;110:63-74.

11. Langervist B, Sylven C, Theodorsen E, Kaijser L, Helmius G, Waldenstrom A. Adenosine induced chest pain: a comparison between intracoronary bolus injection and steady state infusion. Cardiovasc Res 1992;26:810-4.

12. Sylven C, Beermann B, Jonzon B, Brandt R. Angina pectorislike pain provoked by intravenous adenosine in healthy volunteers. Br Med J 1986;293:227-30.

13. Tsukube T, McCully JD, Faulk E, Federman M, LoCicero J, Krukenkamp IB, et al. Warm magnesium cardioplegia reduces cytosolic and nuclear calcium and DNA fragmentation in the senescent myocardium. Ann Thorac Surg 1994;58: 1005-11.

14. Tsukube T, McCully JD, Federman M, Krukenkamp IB, Levitsky S. Developmental differences in cytosolic calcium accumulation associated with surgically induced global ischemia: optimization of cardioplegic protection and mechanism of action. J Thorac Cardiovasc Surg 1996;112:175-84.

15. Ytrehus K, Liu Y, Tsuchida A, Miuura T, Liu GS, Tang X-M, et al. Rat and rabbit heart infarction: effects of anesthesia, perfusion, risk zone, and method of infarct sizing. Am J Physiol 1994;267:H2383-90.

16. Mentzer RM Jr, Bunger R, Lasley RD. Adenosine enhanced preservation of myocardial function and energetics: possible involvement of the adenosine $\mathrm{A}_{1}$ receptor system. Cardiovasc Res 1993;27:28-35.

17. Baxter GF, Marber MS, Patel VC, Yellon DM. Adenosine receptor involvement in a delayed phase of myocardial protection 24 hours after ischemic preconditioning. Circulation 1994;90:2993-3000.

18. Lasley RD, Koyn PJ, Hegge JO, Mentzer RM Jr. Effects of ischemic and adenosine preconditioning on interstitial fluid adenosine and myocardial infarct size. Am J Physiol (Heart Circ Physiol) 1995;269:H1460-6. 
19. Ely SW, Berne RM. Protective effects of adenosine in myocardial ischemia. Circulation 1992;85:893-904.

20. Schubert T, Vetter H, Owen P, Rechart B, Opie LH. Adenosine cardioplegia. J Thorac Cardiovasc Surg 1989;98: 1057-65.

21. Toombs CF, McGee DS, Johnston WE, Vinten-Johansen J. Myocardial protective effects of adenosine. Circulation 1992; 86:986-94.

22. Ito BR, Libaraty DH, Engler RL. Effect of transient coronary occlusion on coronary blood flow autoregulation, vasodilatory reserve and response to adenosine in the dog. J Am Coll Cardiol 1991;18:858-67.

23. Kloner RA, Rude RE, Carlson N, Maroko PR, Deboer LWV, Braunwald E. Ultrastructural evidence of microvascular damage and myocardial cell injury after coronary artery occlusion. Which comes first? Circulation 1980;62:945-52.

24. Hearse DJ, Maxwell L, Saldanha C, Gavin JB. The myocardial vasculature during ischemia and reperfusion: a target for injury and protection. J Mol Cell Cardiol 1993;25:759-800.

25. Fralix TA, Murphy E, London RE, Steenbergen C. Protec- tive effects of adenosine in the perfused rat heart: changes in metabolism and intracellular ion homeostasis. Am J Physiol 1993;264:C986-94.

26. Mullane K, Galifianes M, Hearse DJ. Amplification of endogenous adenosine by "adenosine regulating agents" a therapeutic approach to the treatment of cardiac ischemic syndromes. In: Abd-Elfattah AS, Wechsler AS, editors. Purines and myocardial protection. New York: Kluwer Publishers; 1996. p.231-58.

27. Yao Z, Gross GJ. A comparison of adenosine induced cardioprotection and ischemic preconditioning in dogs: efficacy, time course and the role of $\mathrm{K}_{\mathrm{ATP}}$ channels. Circulation 1994;89:1229-36.

28. Qiu Y, Hearse DJ. Comparison of ischemic vulnerability and responsiveness to cardioplegic protection in crystalloid perfused versus blood perfused hearts. J Thorac Cardiovasc Surg 1992;103:960-8

29. Sandhu R, Diaz RJ, Wilson G. Comparison of ischemic preconditioning in blood perfused and buffer perfused isolated heart models. Cardiovasc Res 1993;27:602-7.

\section{Availability of Journal back issues}

As a service to our subscribers, copies of back issues of The Journal of Thoracic and Cardiovascular Surgery for the preceding 5 years are maintained and are available for purchase from Mosby at a cost of $\$ 16.00$ per issue until inventory is depleted. The following quantity discounts are available: $25 \%$ off on quantities of 12 to 23 , and one third off on quantities of 24 or more. Please write to Mosby, Inc., Subscription Services, 11830 Westline Industrial Drive, St. Louis MO 63146-3318, or call 800-453-4351 or 314-453-4351 for information on availability of particular issues. If unavailable from the publisher, photocopies of complete issues may be purchased from UMI, 300 N. Zeeb Rd., Ann Arbor, MI 48106, 313-761-4700. 